\title{
Microstructure and Mechanical Properties of 18Ni-300 Maraging Steel Fabricated by Selective Laser Melting
}

\author{
Chaolin Tan ${ }^{1,2, \text { a }}$, Kesong Zhou ${ }^{1,2, \mathrm{c} *}$,Xin Tong ${ }^{2, b}$, Yushan Huang ${ }^{1,2}$, \\ Jing $\mathrm{Li}^{1,2}$, Wenyou $\mathrm{Ma}^{2}$, Fuhai $\mathrm{Li}^{2}$, Tongchun Kuang ${ }^{1}$ \\ ${ }^{1}$ School of Materials Science and Engineering, South China University of Technology, Guangzhou, \\ 510640, China
}

${ }^{2}$ Guangdong Institute of New Materials, National Engineering Laboratory for Modern Materials

Surface Engineering Technology, The Key Lab of Guangdong for Modern Surface Engineering Technology, Guangzhou 510651, China.

atclscut@163.com, *bkszhou2004@163.com ctongxin1437@126.com,

Keywords: Additive manufacturing, Selective laser melting, $18 \mathrm{Ni}-300$ alloy, Tensile property.

Abstract: High-strength $18 \mathrm{Ni}-300$ maraging steel parts were fabricated by selective laser melting (SLM) additive manufacturing. Aging treatment at $490^{\circ} \mathrm{C}$ for 6 hours was applied for improving the mechanical properties of SLM fabricated parts. The microstructure and properties of the as-fabricated SLM 18Ni-300 parts were carefully characterized and analyzed. The results show that the relatively low surface roughness, with $4.16 \mu \mathrm{m}$ for horizontal surface and $4.79 \mu \mathrm{m}$ for vertical surface, certified the high accuracy of forming process. The almost fully dense microstructures of the as-fabricated SLM specimens were consisted of sub-micron dendritic cellular structures for horizontal cross-section and elongated acicular structures for vertical cross section. Due to precipitated-phase strengthening, the hardness increased from 35 36 HRC to 51 55 HRC after heat treatment. Meanwhile, the ultimate tensile strength (Rm) increases from $1165 \mathrm{MPa}$ to $2014 \mathrm{MPa}$, which increased by about $73 \%$; while the break elongation ( $\varepsilon$ ) was reduced from $12.44 \%$ to $3.28 \%$, owing to the increased embrittlement caused by the heat treatment. The substantial plastic deformation and dispersively distributed dimples in the fracture morphologies indicated a ductile fracture of as-fabricated tensile specimens, while the age-hardened tensile specimen encountered with a main fracture mode of brittle fracture.

\section{Introduction}

Additive manufacturing (AM), also called 3D printing, is a method of manufacturing in which materials, such as plastic or metal, are deposited onto one another in layers to produce a three dimensional objects $[1,2]$. It integrates multidisciplinary fields including information technology, novel material technology and manufacturing technology [3]. Compared to conventional manufacturing processes, AM processes have many perceived advantages, such as high material and resource efficiency, good part flexibility and production flexibility, economic and environmental friendly $[4,5]$. Due to the irreplaceable superiorities of AM in comparison to other manufacture technologies, it has received considerable attention from both the commercial and academic sectors in the past few decades. And it is continuously being redefined, reimagined and customized to a wide application spectrum such as automotive, aerospace, engineering, medicine, biological systems, and food supply chains, etc. [4, 6, 7].

Selective laser melting (SLM) is a typical metal AM technology, it produce 3-D parts from powdered materials through the application of laser energy to powder beds. The 3-D part geometry derives a stack of 2-D layers, each layer is formed by scanning a laser spot over the required cross-sectional area, and using the laser to selectively melt, sinter and bond particles together in a thin lamina $[8,9]$. After one layer created, another layer of powder will spread on top of the previously processed layer and repeating the scanning process; the subsequent layers are created and simultaneously bonded to already existing layers. The 3-D parts will form after the entire stack of 2-D layers has been created and bonded together. The SLM technology have been wildly applied in 
customized medical parts, tooling inserts with conformal cooling channels and functional components with high geometrical complexity such as porous and lattice constructs [10].

Maraging steels are widely applied in the aircraft industry, aerospace field and tooling applications. Mainly because it combining good material properties like high strength, high toughness, good weldability and dimensional stability during aging heat treatment [11]. The SLM technology is an efficient method to expand application fields and circumstances of maraging steels, such as modes with conformal cooling channels and components with lattice constructs. In this paper, high-strength $18 \mathrm{Ni}-300$ maraging steel parts were fabricated by SLM technique. Aging treatment at $490{ }^{\circ} \mathrm{C}$ for 6 hours was applied for improving the mechanical properties of SLM fabricated parts. The microstructure and mechanical properties of SLM fabricated parts were investigated.

\section{Experimental}

\section{SLM process}

The Maraging Steel 18Ni-300 (MS1) powder with a maximum particle size between 40 50 $\mu \mathrm{m}$ was used as the raw material. The powder was produced by a plasma atomization process and the nominal composition is given in Table 1. The experiments were carried out in an EOS M290 machine equipped with an Ytterbium fibre laser (maximum power, $400 \mathrm{~W}$; beam spot diameter, approx. 0.1 $\mathrm{mm}$; wavelength, 1.06-1.10 $\mu \mathrm{m}$; maximum scanning speed, $7 \mathrm{~m} / \mathrm{s}$ ). Before starting the SLM process, the base plates were pre-heated to $40{ }^{\circ} \mathrm{C}$ by a heater placed inside the building platform, and the oxygen content in the process chamber was maintained under $0.6 \%$ by pumping in continuous nitrogen. The main laser process parameters were set as: laser power, 370-400W; layer thickness, 40 $\mu \mathrm{m}$; beam spot diameter, $100 \mu \mathrm{m}$. The schematic diagram of the SLM process is shown in Fig.1. As mentioned above, aging heat treatment can effectively improve the performance of maraging steel, so the as-fabricated specimens were heat treated at $490{ }^{\circ} \mathrm{C}$ and 6-hour duration for age-hardening.

Table 1 Chemical composition of $18 \mathrm{Ni}-300$ maraging steel.

\begin{tabular}{llllllllll}
\hline Element & $\mathbf{N i}$ & $\mathbf{C o}$ & $\mathbf{M o}$ & $\mathbf{T i}$ & $\mathbf{A l}$ & $\mathbf{C}$ & $\mathbf{C r}, \mathbf{C u}$ & $\mathbf{S i}, \mathbf{M n}$ & $\mathbf{S}, \mathbf{P}$ \\
\hline wt. $/ \%$ & $17-19$ & $8.5-9.5$ & $4.5-5.2$ & $0.6-0.8$ & $0.05-0.15$ & $\leq 0.03$ & $\leq 0.5$ & $\leq 0.1$ & $\leq 0.01$ \\
\hline
\end{tabular}

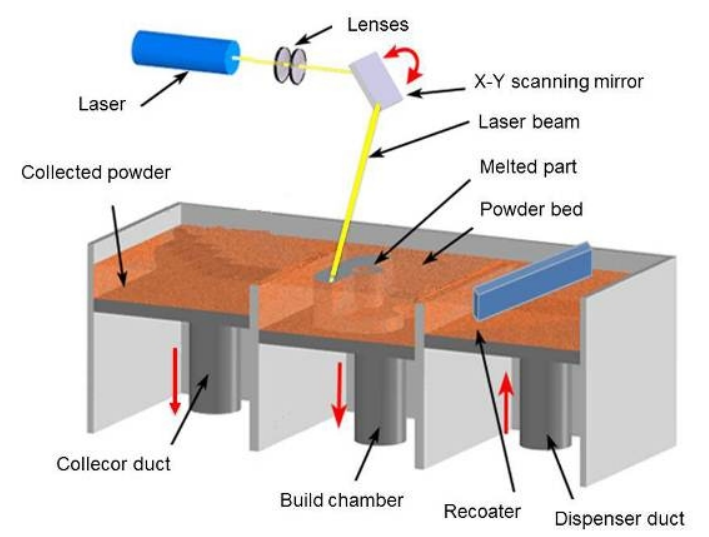

Fig.1. The schematic diagram of the SLM process in EOS M290 machine.

\section{Characterization}

The un-polished fresh morphologies of vertical and horizontal cross sections (to the building plane) of the SLM specimens were characterized by a Zeiss Merlin field emission scanning electron microscope (FE-SEM), fitted with an Oxford energy dispersive spectrometer (EDS). The surface profiles of fresh vertical and horizontal cross sections of the specimens were characterized by a BMT SMS Expert 3-D model optical profilometer to evaluate the roughness $\mathrm{Sa}$. The polished and etched vertical and horizontal cross sections were observed by a Leica Dmirm optical microscope (OM) and the FE-SEM for microstructures investigation.

The hardness of the specimens was measured by a TH320 Rockwell hardness tester according to the $150 \mathrm{~kg}$ loaded Rockwell C scale (HRC), and estimated by an average value from 10 measured points. The mechanical properties were evaluated by tensile tests with an Instron 5900 universal 
material testing machine in accordance with ASTM E8 [12]. The cross head speed in the tensile tests was $1 \mathrm{~mm} / \mathrm{min}$. Fracture morphologies of SLM fabricated specimens were investigated by FE-SEM.

\section{Results and discussion}

\section{Surface mophology}

The surface roughness acts as an important role in affecting the modeling accuracy of parts fabricated by SLM process. Therefore, to characterize and evaluate the surface conditions are of great importance. Fig. 2 shows the non-polished fresh morphologies and roughness of SLM fabricated 18Ni-300 alloy specimens. The paralleled laser tracks are evident exhibited in Fig. 2a, the saturated narrow strips are overlap zone of two laser irradiation tracks. The horizontal surface roughness Sa, examined from an $2 \mathrm{~mm} \times 2 \mathrm{~mm}$ area, is about $4.16 \mu \mathrm{m}$ (Fig. 1b). There are many unmelted powder particles adsorbed on the vertical surface (Fig. 2c), for the reason that the fabrication process is embedded in the powder bed, and the powders without laser scanning are easily attached to the cross-section of uncooled sintered layers. The vertical surface roughness Sa, also examined from an $2 \mathrm{~mm} \times 2 \mathrm{~mm}$ area, is about $4.79 \mu \mathrm{m}$ (Fig. $2 \mathrm{~d}$ ). The lowly surface roughness certified the high accuracy of forming process.
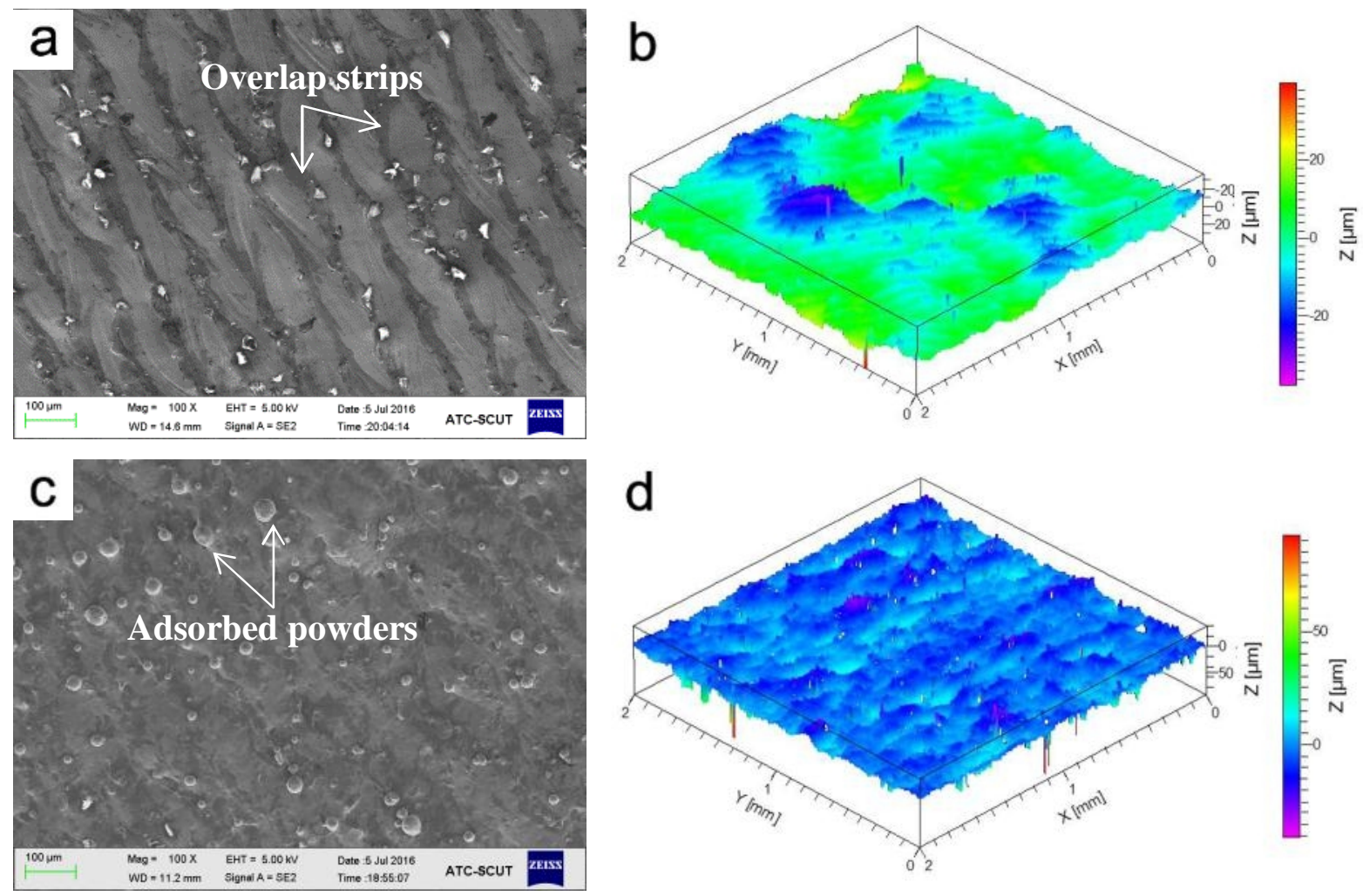

Fig.2. Surface morphologies and roughness of the SLM fabricated specimen. Macro-morphology (a) and roughness (b) of the horizontal surface; macro-morphology (c) and roughness (d) of the vertical surface

\section{Microstructure analysis}

Fig. 3 shows the typical optical micrographs of the polished and etched horizontal and vertical cross sections of the $18 \mathrm{Ni}-300$ SLM fabricated specimen. There are scarcely any micropores or defects of the $18 \mathrm{Ni}-300$ specimen, and it is almost a fully dense part. The microstructure observations of horizontal cross section were ellipsoid braided structures, shown in the Fig. 3a, the ellipsoids are about $90-100 \mu \mathrm{m}$, which are equal in width to the laser spot diameter (about $100 \mu \mathrm{m}$ ). As shown in Fig. $3 \mathrm{~b}$, the microstructures in the vertical cross section are flaky half-ellipses with dimension of $40-50 \mu \mathrm{m}$ in height and 80-100 in base width. The height of half-ellipses are approximately equal to the powder layer thickness and the base widths are approximately equal to laser spot diameter. Thus, it reflects the profile for the laser melting pool of the $400 \mathrm{~W}$ laser radiation on $40 \mu \mathrm{m}$ thickness powder layer. 
Fig. 4 shows high-magnification microstructural SEM images of the (a) horizontal and (b) vertical cross sections at the center of a laser scanning track on the specimen of Fig. 3. The sub-micron sized fine dendritic cellular microstructures with size of approx. $0.2-0.6 \mu \mathrm{m}$ could be observed in the horizontal cross section (Fig. 4a). While, the vertical cross section exhibits elongated acicular microstructures along the melting layer stacking direction. These fine cellular and acicular microstructures are exclusive to the SLM process, it would form in response to the instant melting and rapid solidification with extreme high cooling rate of the powder alloy during the laser irradiation[13].
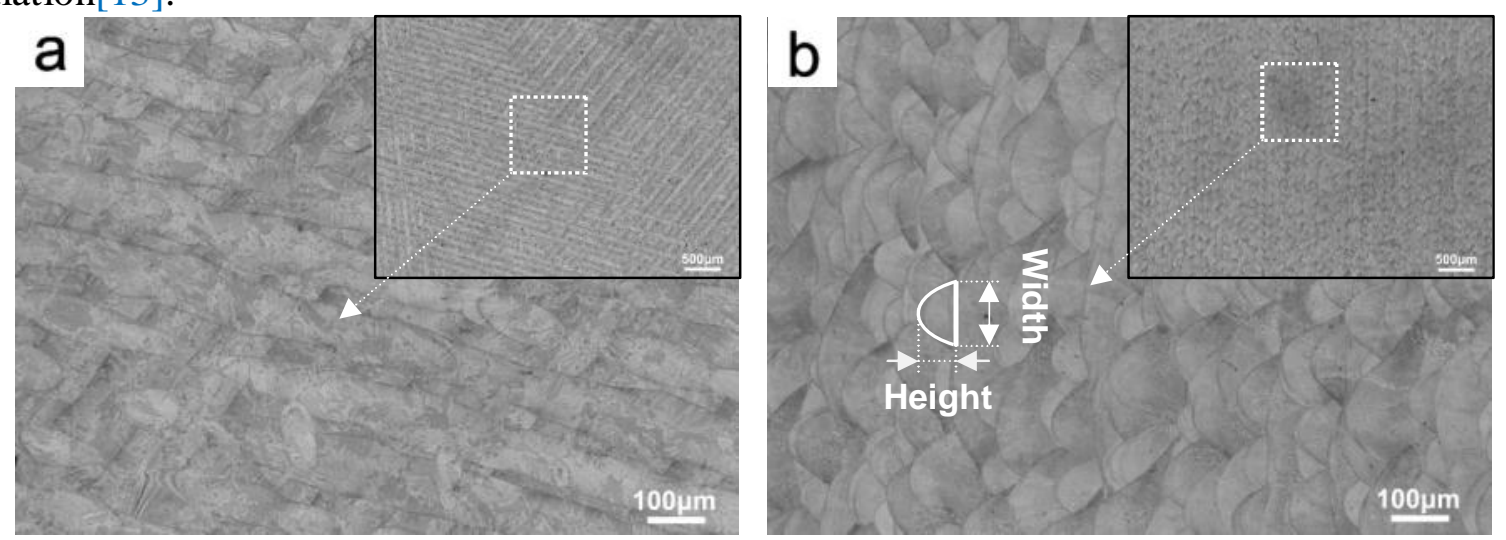

Fig.3. Optical micrographs of the horizontal cross-section (a) and vertical cross-section (b) of the SLM fabricated specimen.
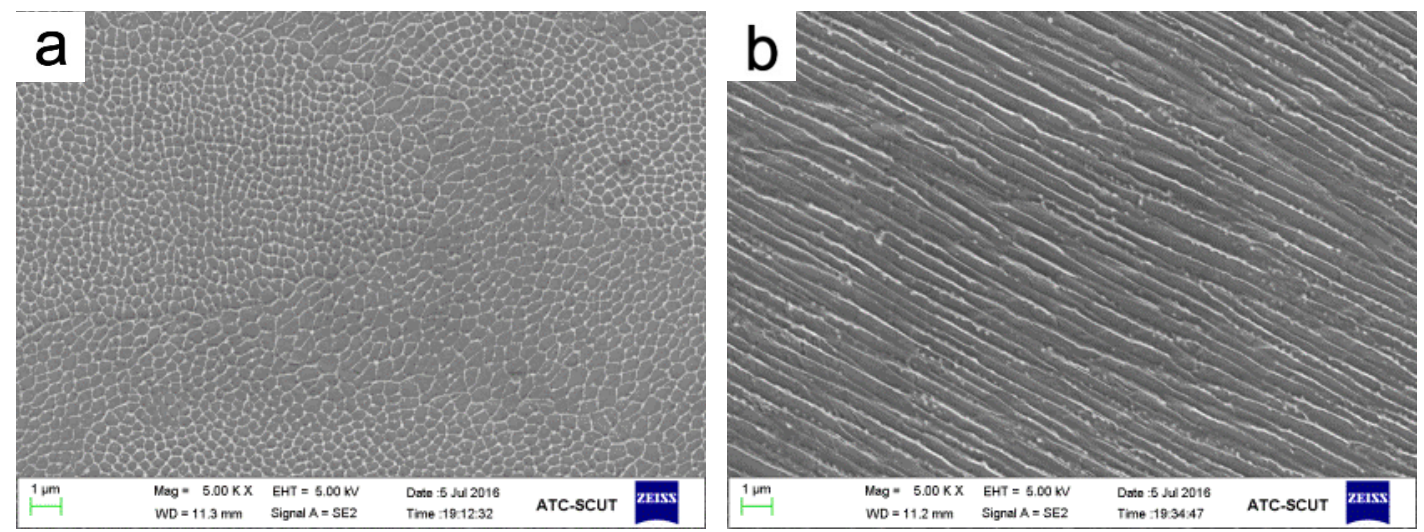

Fig.4. SEM images of the horizontal cross-section (a) and vertical cross-section (b) of the SLM fabricated specimen. Hardness analysis

The hardness features for horizontal and vertical cross sections of the as-fabricated and heat-treated SLM 18Ni-300 alloy specimen are displayed in Fig. 5. The as-fabricated specimen is ranging from $35 \sim 36 \mathrm{HRC}$, while the hardness of specimen raises to 51 55 $\mathrm{HRC}$ after heat treated at $490{ }^{\circ} \mathrm{C}$ and 6-hour duration for age-hardening. The cellular structures with intercellular spacing of less than $1 \mu \mathrm{m}$ (Fig. 4a), made great contribution to the excellent strength and hardness. The statements are also validated by other researchers $[11,14]$. The heat treatment significantly improved the hardness of SLM fabricated $18 \mathrm{Ni}-300$ alloy. The aging heat treatment is a standard for maraging steels, in the low-carbon body-centered cubic (bcc) martensite structure, there will form a uniform distribution of fine $\mathrm{Ni}$, Co and Mo rich intermetallic precipitates during the aging of the martensite. These precipitates serve to strengthen the martensitic matrix [11]. Therefore, the precipitated-phase strengthening is the main hardening mechanism of $18 \mathrm{Ni}-300$ alloy during aging heat-treatment. 


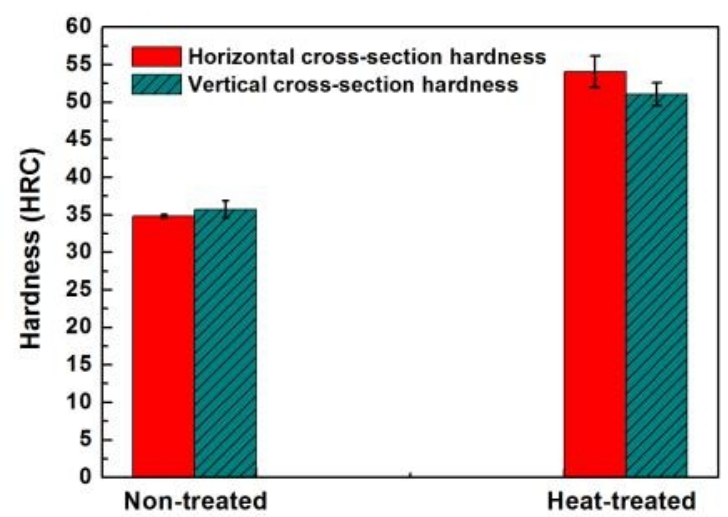

Fig.5. Hardness of the non-treated and heat-treated SLM fabricated specimens.

\section{Tensile properties and fracture analysis}

The representative engineering stress-strain curves of specimens under uniaxial tension, extracted from the as-fabricated and heat-treated SLM 18Ni-300 alloy, are shown in Fig. 6. The measured mechanical properties are summarized in Table 2. Aging for 6 hours at $490^{\circ} \mathrm{C}$ leads to an improvement of tensile performances. The ultimate tensile strength (Rm) increases from $1165 \mathrm{MPa}$ to $2014 \mathrm{MPa}$, which increased by about $73 \%$. However, the break elongation $(\boldsymbol{\varepsilon})$ was reduced from $12.44 \%$ to $3.28 \%$ after aging heat treatment, which indicated that the strength of aging-treated $18 \mathrm{Ni}-300$ alloy was well enhanced while the ductility was seriously reduced.

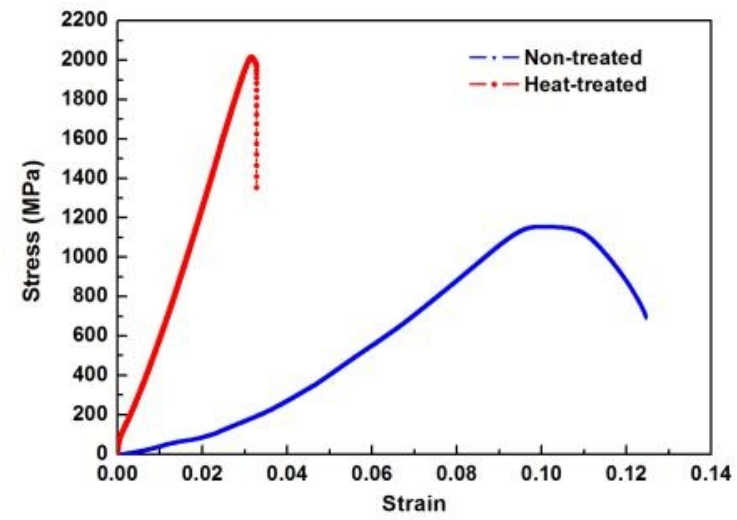

Fig.6. Engineering stress-strain curves of non-treated and heat-treated SLM fabricated specimens.

Table 2 Mechanical properties of SLM fabricated 18Ni-300 steel.

\begin{tabular}{lllll}
\hline Specimens & $\mathbf{R m}(\mathbf{M P a})$ & $\mathbf{R p}_{\mathbf{0 . 2}}$ (MPa) & $\boldsymbol{\varepsilon}(\boldsymbol{\%})$ & HRC \\
\hline SLM & $1165 \pm 7$ & $1967 \pm 11$ & $12.44 \pm 0.14$ & $35 \sim 36$ \\
SLM + aging & $2014 \pm 9$ & $915 \pm 7$ & $3.28 \pm 0.05$ & $51 \sim 55$ \\
\hline
\end{tabular}

As revealed in Fig. 7, the embrittlement, caused by the heat treatment, is also exhibited in the fractographies. The non-treated specimen broke after substantial plastic deformation, and the dimples are formed in the fracture morphologies (Fig. 7a), which is a typical ductile fracture. A ductile fracture is always trans-granular. During the tensile process, the specimen undergoes a large plastic deformation and the micro-cavities arise at the precipitates or imperfections. At the same time, large stresses, caused by the cavities, will lead to more micro-cavities in return. Eventually, the cavities conjoin together and the fast growing tears cause the fracture. As for the age-hardened specimen, shown in Fig. 7b, the dimples are shallow and plastic deformation is insufficient. Both trans-granular and inter-granular fractures appear in the fracture morphology. So the main fracture mode is brittle fracture. Although, the ductile of as-fabricated 18Ni-300 SLM parts were decreased, the enhanced hardness and tensile strength are more attractive for its applications, such as modes, tools and mechanical components. 

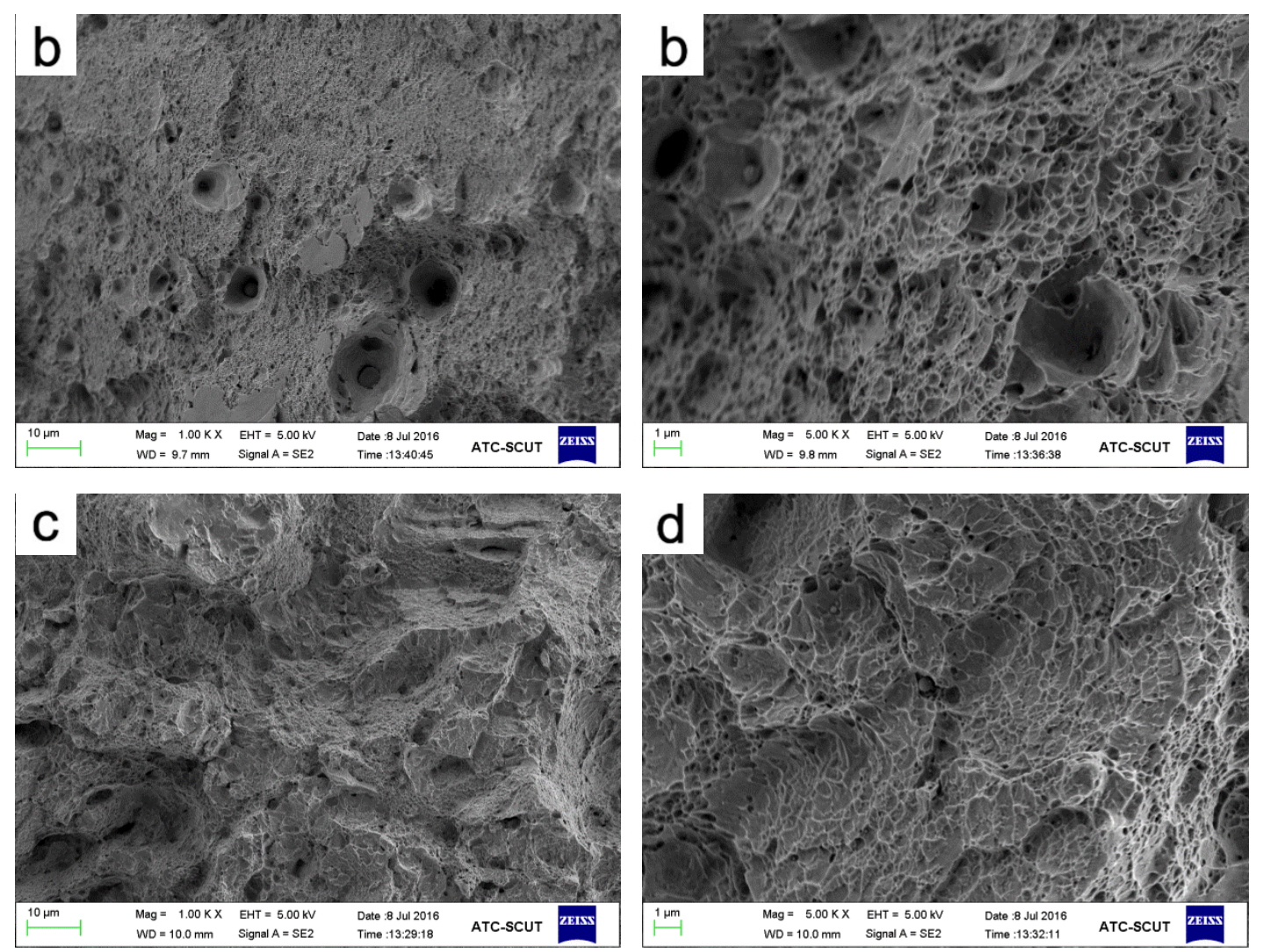

Fig.7. Fracture morphologies of (a) (b) non-treated and (c) (d) heat-treated SLM fabricated specimens.

\section{Conclusions}

High-strength 18Ni-300 maraging steel parts were fabricated by selective laser melting (SLM) additive manufacturing. The mechanical properties of the as-fabricated 18Ni-300 SLM parts were observably improved by applying aging treatment at $490^{\circ} \mathrm{C}$ for 6 hours. The primary conclusions are:

(1) The relatively low surface roughness, with $4.16 \mu \mathrm{m}$ for horizontal surface and $4.79 \mu \mathrm{m}$ for vertical surface, certified the high accuracy of forming process. The microstructures of the as-fabricated SLM specimens were consisted of sub-micron dendritic cellular structures for horizontal cross-section and elongated acicular structures along the stacking direction for vertical cross section.

(2) After heat treatment, the hardness increased from 35 36 HRC to 51 55 HRC due to precipitated-phase strengthening. Meanwhile, the ultimate tensile strength $(\mathrm{Rm})$ increases from 1165 $\mathrm{MPa}$ to $2014 \mathrm{MPa}$, which increased by about 73\%; while, the break elongation ( $\varepsilon$ ) was reduced from $12.44 \%$ to $3.28 \%$, for the increased embrittlement caused by the heat treatment. Fracture morphologies revealed that plastic deformation and the dimples in the as-fabricated tensile specimens indicated a ductile fracture, while the age-hardened tensile specimen encountered with a main fracture mode of brittle fracture. The enhanced hardness and tensile strength are more attractive for its applications, such as modes, tools and mechanical components.

\section{Acknowledgements}

This work was financially supported by the Key Scientific and Technical Innovation Project of Guangdong (2015B010122004), Special fund project of Applied Technical Research and Development of Guangdong (2015B090920003), National Natural Science Foundation of China (51501044), Guangzhou Pearl River S\&T Nova Project (2014J2200095), Sciences Platform Environment and Capacity Building Projects of GDAS (2016GDASPT-0317 and 
2016GDASPT-0206) and Guangdong province Science and Technology Plan Projects (2016B070701020). This work was also supported by 2013B061800053 and 2014B070706026.

\section{References}

[1] W.E. Frazier, Metal Additive Manufacturing: A Review, Journal of Materials Engineering and Performance, 23 (2014) 1917-1928.

[2] S.M. Thompson, L. Bian, N. Shamsaei, A. Yadollahi, An overview of Direct Laser Deposition for additive manufacturing; Part I: Transport phenomena, modeling and diagnostics, Additive Manufacturing, 8 (2015) 36-62.

[3] J. Stampfl, M. Hatzenbichler, Additive Manufacturing Technologies, in: L. Laperrière, G. Reinhart (Eds.) CIRP Encyclopedia of Production Engineering, Springer Berlin Heidelberg, Berlin, Heidelberg, 2014, pp. 20-27.

[4] S.H. Huang, P. Liu, A. Mokasdar, L. Hou, Additive manufacturing and its societal impact: a literature review, The International Journal of Advanced Manufacturing Technology, 67 (2012) 1191-1203.

[5] B. Berman, 3-D printing: The new industrial revolution, Business Horizons, 55 (2012) 155-162. [6] W. Gao, Y. Zhang, D. Ramanujan, K. Ramani, Y. Chen, C.B. Williams, C.C.L. Wang, Y.C. Shin, S. Zhang, P.D. Zavattieri, The status, challenges, and future of additive manufacturing in engineering, Computer-Aided Design, 69 (2015) 65-89.

[7] M.G. Rashed, M. Ashraf, R.A.W. Mines, P.J. Hazell, Metallic microlattice materials: A current state of the art on manufacturing, mechanical properties and applications, Materials \& Design, 95 (2016) 518-533.

[8] E.O. Olakanmi, R.F. Cochrane, K.W. Dalgarno, A review on selective laser sintering/melting (SLS/SLM) of aluminium alloy powders: Processing, microstructure, and properties, Progress in Materials Science, 74 (2015) 401-477.

[9] D.D. Gu, W. Meiners, K. Wissenbach, R. Poprawe, Laser additive manufacturing of metallic components: materials, processes and mechanisms, International Materials Reviews, 57 (2013) 133-164.

[10] H.B. Li Huaixue, Sun Fan, Gong Shuili Microstructure and Tensile Properties of Ti-6Al-4V Alloys Fabricated by Selective Laser Melting, Rare Metal Materials and Engineering 42 (2013) 209-212

[11] K. Kempen, E. Yasa, L. Thijs, J.P. Kruth, J. Van Humbeeck, Microstructure and mechanical properties of Selective Laser Melted 18Ni-300 steel, Physics Procedia, 12 (2011) 255-263.

[12] ASTM Standard E8/E8M-2015a: Standard Test Methods for Tension Test of Metallic Materials, ASTM International, West Conshohocken, PA, 2015.

[13] T. Kimura, T. Nakamoto, Microstructures and mechanical properties of A356 (AlSi7Mg0.3) aluminum alloy fabricated by selective laser melting, Materials \& Design, 89 (2016) 1294-1301.

[14] M. Stanford, Kibble, K. , Lindop, M. , Mynors, D. ,Durnall, C, An investigation into fully melting a maraging steel using direct laser sintering, Metal Forming Conference, (2008) 847-852. 